\title{
From the Editors: Explaining interaction effects within and across levels of analysis
}

\author{
Ulf Andersson ${ }^{1}$, Alvaro \\ Cuervo-Cazurra ${ }^{2}$ and \\ Bo Bernhard Nielsen ${ }^{3}$
}

${ }^{1}$ Area Editor; ${ }^{2}$ Reviewing Editor

${ }^{3}$ Consulting Editor

Correspondence:

A Cuervo-Cazurra, D'Amore-McKim School of Business, Northeastern University, 313 Hayden Hall, 360 Huntington Avenue, Boston, MA 02115, USA.

Tel: 0016173736568 ;

Fax: 0016173738628 ;

email: a.cuervocazurra@neu.edu

\begin{abstract}
Many manuscripts submitted to the Journal of International Business Studies propose an interaction effect in their models in an effort to explain the complexity and contingency of relationships across borders. In this article, we provide guidance on how best to explain the interaction effects theoretically within and across levels of analysis. First, in the case of interactions within the same level of analysis, we suggest that authors provide an explanation of the mechanisms that link the main independent variable to the dependent variable, and then explain how the interaction variable modifies these mechanisms. Moreover, to ensure that the arguments are theoretically complete, we suggest that authors theoretically rule out the potential reverse interaction effect between the main variable and moderating variable. Second, in the case of interactions across levels of analysis, we suggest that authors identify the cross-level nature of the moderating relationships, specify the level of analysis of the main relationship and the nested nature of the cross-level influences, and theoretically explain these cross-level influences. Additionally, we suggest that authors pay particular attention to nesting in order to theoretically rule out reverse interactions.
\end{abstract}

Journal of International Business Studies (2014) 45, 1063-1071. doi:10.1057/jibs.20I4.50

Keywords: interaction effects; moderation effects; cross-level interaction; international business; theory development

\section{INTRODUCTION}

As editors, we are increasingly seeing papers with interaction effects - also known as multiplicative effects, product terms or moderation effects - that benefit from the powerful statistical analyses now available to scholars. Such research strategy has the potential to yield new theoretical insights that may advance the international business (IB) field. However, incorporating interaction effects is challenging because it identifies new and complex relationships that needs to be adequately explained. To help authors, in this editorial we provide suggestions for how best to explain the theoretical mechanisms ${ }^{1}$ behind proposed interaction effects in order to clarify the theoretical contribution of their studies. We go beyond statistical explanations of interaction effects and their detection (see, e.g., Aguinis \& Gottfredson, 2010; Jaccard \& Turrisi, 2003; Shieh, 2009), which, depending on how the variables are measured and the type of statistical method used, can be quite challenging.

We discuss two types of interaction effects: within and across levels of analysis. First, for interactions within levels of analysis, we 
suggest that authors first provide an explanation of the theoretical mechanisms that link the main independent variable to the dependent variable, and then explain how and why the interaction variable modifies these theoretical mechanisms. Additionally, we suggest that authors theoretically rule out the existence of a reverse interaction effect in which the independent variable is actually affecting the relationship between the moderator and dependent variable. Second, for interactions across levels of analysis, we suggest that authors first identify the level of analysis of the main relationship, then specify the cross-level nature of the moderating relationships, before clarifying the hierarchy and nature of theoretical nesting. In addition, we propose that authors theoretically explain the multilevel influences, separating the justification of the cross-level interaction effect from the explanation of the cross-level direct influences.

\section{EXPLAINING INTERACTION EFFECTS}

\section{Interaction Effects}

Generally, interaction is said to occur when the effect of an independent variable $(X)$ on a dependent variable $(Y)$ varies across levels of a moderating variable $(Z)$. Identifying and specifying relevant and important interaction effects pertaining to relations between independent and dependent variables is at the heart of theory in social science (Cohen, Cohen, West, \& Aiken, 2003) and indicates the maturity and sophistication of a field of inquiry (Aguinis, Boik, \& Pierce, 2001). Interactions provide researchers with the ability to enrich our understanding of economic and social relationships by establishing the conditions under which such relationships apply, or are stronger or weaker. As such, interactions enable the extension of well-known relationships to contexts that the original research did not consider, and they also help provide more detailed predictions about the relationships, going beyond the simplistic argument "it depends". However, merely detecting a statistically significant effect of the interaction between independent and moderating variables on the dependent variable is not sufficient to be considered a contribution to the literature. The interaction effect has to be explained, and there must be theoretical arguments for why including this interaction results in better theory.

Research questions involving moderators typically address "when" or "under what conditions" an independent variable most strongly influences an outcome variable. More specifically, a moderator is a variable that alters the nature or strength of the relationship between an independent and an outcome variable (Baron \& Kenny, 1986). The distinction between circumstances where the nature of the relationship of $X$ on $Y$ varies as a function of $Z$ (differential prediction) vs the strength of the relationship of $X$ on $Y$ varies as a function of $Z$ (differential validity) is important for several reasons. First, only differential prediction is appropriately tested with moderated multiple regression, which is the statistical test typically employed in moderation studies (Carte \& Russell, 2003). Differential validity is typically tested via subgroup moderation: the sample is split into two or more groups based on the level of the moderator variable, and $t$-tests of the correlation coefficients and $\chi^{2}$ tests are performed to assess the strength of the moderation effect and differences among groups. Second, the language and argumentation employed in moderation hypotheses is often inaccurate in relation to the actual tests performed. For instance, if a researcher asserts that "the strength of the multinationality-performance relationship depends on the level of product diversification", then he/she must report differences in strength of the multinationality-performance relationship (i.e., $r_{\text {multinationality-performance) across levels of }}$ product diversification rather than the often-reported differences in the slope (nature) of the multinationality-performance relationship across levels of product diversification. Scholars must specify the role of the moderation a priori and make sure that the language, theoretical argumentation, and ensuing empirical tests match.

The choice of the moderating variable should be based on a specific theory regarding why, or under what conditions, a given relationship may be significantly influenced for some types of firms, teams, or individuals rather than for others. This choice is important because it drives the specific type of interaction that needs to be explained. First, there are interactions between two continuous variables, which can take three typical patterns (Cohen et al., 2003: 285-286): (a) enhancing interactions, in which both the predictor and moderator affect the outcome variable in the same direction and together they have a stronger effect than a merely additive one; (b) buffering interactions, in which the moderator variable weakens the effect of the predictor variable on the outcome; and (c) antagonistic interactions, in which the predictor and moderator have the same effect on the outcome but the interaction is in the opposite direction. Second, there are interactions between a categorical variable and a continuous variable, which can take two different 
patterns: (a) existence interaction, when an independent variable is positively related to the dependent variable for one particular group but unrelated for another group; and (b) competing interactions, when an independent variable is positively related to the dependent variable for one particular group but it is negatively related for another.

The distinction between the different patterns of interaction has important implications for theory, as the selection of the particular type of interaction should be driven by the specific nature of the concepts analyzed rather than by the particular measurement of the variables used in the statistical analysis. Although all interaction types have the potential for advancing theory, the buffering and antagonistic interactions between continuous variables, and the competing interaction between a categorical variable and continuous variable, hold the greatest potential because they are more likely to challenge existing theory.

\section{Challenges in Explaining Interactions}

Regardless of the particular type of interaction proposed, the following are some of the common challenges we find in the explanation of interaction effects in many initial drafts of manuscripts that propose an interaction.

First, there is often no explanation of, or indeed theoretical justification for, the direct effect. Far too often, manuscripts simply start with an explanation of the interaction effect. One reason for this may be that the authors think that the novelty of the paper resides in the interaction effect, because the direct effect has been explained in detail and tested before. However, this approach is problematic because the theoretical mechanism explaining the baseline argument remains unspecified. As a result, it becomes unclear what baseline effect the interaction is supposed to modify. This is particularly problematic because many management and IB phenomena can be explained from many alternative theoretical perspectives; the different mechanisms that link the independent variable to the dependent variable may be rooted in different theories, which offer different logics even if they end up resulting in the same hypothesized relationship. For instance, the relationship between multinationality and performance can be explained from the theoretical standpoints of internalization theory (Buckley \& Casson, 1976), behavioral theory of internationalization (Johanson \& Vahlne, 1977), or resource-based view (Penrose, 1959), among others. While related, each theory argues for different mechanisms explaining the performance consequences of multinationality, so the explanation of the moderating variable's influence will also differ depending on the theory considered. For example, if one considers product diversification as a moderator, the challenge is to decide which mechanism it changes: product diversification may alter the costs of multinationality, the risks of multinationality, or the benefits from leveraging firm resources across markets; the choice depends on the theory used to explain the baseline multinationality-performance relationship. Moreover, different theories may actually specify opposing main effects in certain cases; in such cases, failure to specify the nature and direction of the main relationship renders any theorizing or interpretation of the interaction effects ambiguous at best. Such instances may be particularly problematic because even when the direct effect is not statistically significant while the interaction is, the direct relationships must be theoretically justified and described in order for the interaction to make sense.

Second, many manuscripts explain the direct effect of the moderating variable on the dependent variable rather than the impact of the moderating variable on the relationship between the independent and dependent variables. Since manuscripts proposing interaction effects often introduce a new variable, authors often start by defining the new variable and then provide a review of studies that have discussed its impact on the dependent variable; however, these are explanations of a direct effect rather than a moderation effect. In some cases authors end the explanation with a couple of statements along the lines of "since the independent variable has an impact on the dependent variable and the moderating variable also has an impact on the dependent variable, one can conclude that the moderating variable interacts with the independent variable to affect the dependent variable, leading to a hypothesis that argues for the interaction". However, such explanatory strategy does not actually provide an explanation of the interaction per se. A moderator or interaction variable may or may not have an effect on the dependent variable (Carte \& Russell, 2003); moreover, the independent and moderator variables should not be theoretically related as this would imply mediation (Baron \& Kenny, 1986). Thus, the arguments for a variable's moderating effect on the main relationship must be distinct from its direct effect on the dependent variable, and if there is a relationship between the moderator and dependent variable, the underlying theoretical mechanism linking them must differ from the 
theoretical mechanism that influences the main relationship.

Third, some papers face the challenge that although they discuss the relationship between independent and moderating variables on the dependent variable, they do not actually explain the direction of the relationship in the interaction effect. This is problematic especially when the direction of causality can theoretically go both ways. As a result of not specifying theoretically the direction of the relationship, it is unclear which is the main mechanism and which is the interaction effect. A discussion of how the variables have been found to be related to each other in previous research, or indeed how the interaction among variables has been found to be statistically significant in previous studies, does not qualify as an explanation of causality. Most of the interaction effects are statistically analyzed by simply multiplying the independent and moderating variables and studying how this product term affects the dependent variable. While the empirical results are the same, the theoretical implications of the direction of causality are not equivalent, and conclusions and recommendations drawn from an inaccurate causality relationship may be erroneous.

\section{Recommendations for Explaining Within-Level Interaction Effects}

The typical figure explaining a within-level interaction effect appears in Figure 1. This representation is commonly found in manuscripts in which the relationship between the independent variable of interest $(X)$ and the dependent variable $(Y)$ is argued to be modified by some other variable $(Z)$. This simple representation then results in one or two hypotheses being discussed and formally presented in the paper. The first hypothesis tends to be the direct effect, predicting the impact of the independent variable of interest on the dependent variable. The second hypothesis is the moderation effect, predicting the strengthening or weakening of the direct effect under the moderating condition (see Cuervo-Cazurra \& Dau, 2009, as an illustration).

Although parsimony can be useful, authors need to be careful and avoid oversimplifying to the point of making simplistic arguments. Figure 2 presents some of the potential additional relationships that may have an influence on the explanation of the moderating relationships and that need to be theoretically addressed: the direct effect of the moderating variable on the dependent variable, the reverse interaction (i.e., the independent variable becoming the moderating variable), and alternative

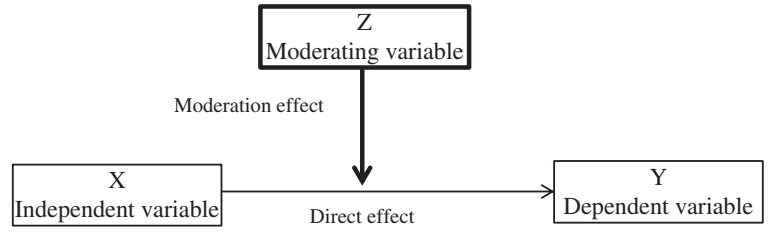

Figure 1 Typical relationships in a within-level moderation model.

Note: The thicker line is the relationship of focus.

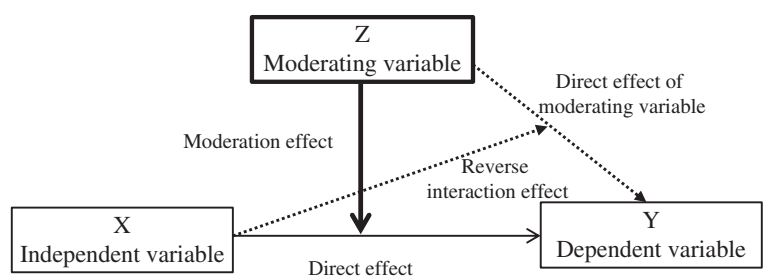

Figure 2 Additional relationships in need of theoretical explanation when analyzing a within-level moderation model.

Note: Dashed lines indicate alternative relationships to consider.

explanations for the moderation effect. Although other relationships, such as mediation and additional exogenous variables, may also have an effect on the moderation, they are beyond the scope of this article.

We now provide a sequence of steps that authors can use to ensure that the interaction effects are clearly explained. In some cases, there is little empirical literature one can use to justify the proposed relationship. In such cases, it is even more important that the moderation effect is clearly explained and that the choice of moderating variables, as well as the proposed nature and effects of these on the direct relationship, is clearly guided by theory. This does not imply that the explanation should not include citations, but rather that the author needs to outline and articulate the underlying theoretical basis of the conceptual mechanisms to explain the interaction. We suggest the following steps to explain within-level moderation:

1. First, identify the theory or theories that are used to explain the direct and moderating effects. Clearly stating the theory used, the logic for using such theory, and an outline of the key arguments and assumptions of the theory not only helps the author clarify the theoretical approach used to build hypotheses, but also helps the reader understand how the author explains the arguments.

2. Second, apply the selected theory to the research question and explain the direct effect and the 
mechanisms behind it. The explanation of the mechanisms requires statement such as "variable $x$ has a positive effect on variable $y$, because ...". This does not imply a discussion of how the variables are related, but rather one of why they are related and why the causality goes in a particular direction. If the direct effect has been widely analyzed before and there is a consensus on the relationship from the theoretical standpoint, you may state that this is a well-known argument, and that the direct effect is merely a baseline hypothesis.

3. Third, provide a theoretical justification for the choice of moderator variable. The inclusion of moderating effects in the analysis must be driven by theory rather than by the existence of previous empirical studies that have discussed such interaction, or by the statistical significance of the interaction term in the statistical analysis. The moderating variable establishes conditions under which the direct effect varies, and thus its selection needs to be within the realm of the theory used. Even if you find a statistically significant interaction effect, this does not mean that the moderating variable is theoretically justified; you may be finding such effect because there is mediation or because there is a common determinant (for a discussion, see Frazier, Tix, \& Barron, 2004).

4. Fourth, explain the direct effect, if any, of the moderator variable on the dependent variable so that it is clear how this direct effect differs from the interaction effect. Although this may be a well-explained relationship, you still need to clarify the mechanisms that lead the moderating variable to affect the dependent variable. As with the direct effect, you may want to present a separate baseline hypothesis if it is relevant. These mechanisms need to differ not only from the mechanisms explaining the interaction effect, but also from the mechanisms explaining the direct effect of the independent variable on the dependent variable.

5. Fifth, explain how the interaction changes the mechanisms that explain the direct relationship. Using theory, specify arguments such as "the impact of $X$ on $Y$ is strengthened when $Z$ is present because $Z$ changes the mechanism in this manner ..." or "the influence of $X$ on $Y$ is reduced in the presence of $Z$ because the mechanism is weakened in this way ...". Conceptualized as a contingency hypothesis, moderation can be used to examine the boundaries and limitations of a theory (Boyd, Haynes, Hitt, Bergh, \& Ketchen,
2012). In this way, moderation specifies the conditions under which a given theory applies (or not) and thus increases the precision of theoretical predictions (Edwards, 2010). Again, make sure that the explanation of the interaction effect differs from the explanation of the direct effect as well as from the explanation of the impact of the moderating variable on the dependent variable.

6. Sixth, theoretically rule out the reverse interaction in which the independent variable $X$ is moderating the relationship between the moderating variable $Z$ and the dependent variable $Y$. This of course only becomes an issue if a theoretical rationale exists for linking $Z$ to $Y$, which we discussed in point four above. The theoretical challenge is to argue that the moderation can only exist in one direction and not the other, for example, because the moderator operates at a different level of analysis or temporally precedes the relationship. Phrase the hypotheses and graph the interactions in a way that is consistent with the theoretically grounded direction of the moderating relationship (Aguinis, Gottfredson, \& Culpepper, 2013).

7. Seventh, return to theory when interpreting the results and explain them from a theoretical viewpoint. Rather than state the usual "hypothesis $x$ is supported because the coefficient of the interaction term is statistically significant", put far more emphasis on the substantive meaning of such results in terms of our theoretical understanding of the phenomenon under investigation. Specify whether the nature and/or strength of the focal relationship changed as a result of the inclusion of the interaction and how such results inform theory and research moving forward. Non-significant results from the inclusion of moderation effects may also provide useful insights.

\section{Recommendations for Explaining Cross-Level Interaction Effects}

Multilevel studies involve relationships between independent and dependent variables at different levels; thus cross-level relationships can be direct and/or moderating. Applying multilevel lenses requires both conceptual and analytical considerations (Snijders \& Bosker, 2012).

The cross-country nature of IB is particularly ripe for multilevel studies and cross-level interactions (Peterson, Arregle, \& Martin, 2012). Multilevel theorizing provides ample opportunities for 
cross-fertilization of theories originating from different disciplines; at the same time it requires careful attention to the underlying assumptions of those theories. One typical use of cross-level interaction in IB is the analysis of the impact of country-level variables on firm-level behavior. A baseline hypothesis may be grounded in well-known IB theory, with the contribution to the literature coming in the form of a modification of the expected relationship based on insights from another theory that operates at a different level.

However, simply adding another moderating variable, even at a different level of theory, does not constitute a theoretical contribution per se. While borrowing concepts and variables from different disciplines may yield new insights, an in-depth appreciation for the underlying theory and rigorous integration with IB theory is paramount (Bello \& Kostova, 2012; Cheng, Henisz, \& Roth, 2009). It is critical to avoid committing the error of "rebottling old wine in new bottles"; that is, selecting variables that have previously been studied in similar settings. Variables and concepts from other levels or disciplines are often part of a system of constructs that together make up a theory; separating (i.e., cherry picking) one or two of these constructs and utilizing them in an isolated fashion as moderators in IB studies violate the underlying coherence of the theory and constructs and may lead to flawed theorizing. Moreover, though drawing on concepts from theories at different levels holds much promise for advancing IB theory, and we certainly promote such theorizing, careful attention must be paid to the ability of theoretical constructs to traverse levels without losing their substantive meaning. Key constructs may be subject to different meanings at different levels, in different cultures and environments, or between headquarters and subsidiaries.

The prevailing logic in management is that the larger context within which organizations are embedded exerts a greater downward influence than vice versa (Mathieu \& Chen, 2011). In cross-level research, accurately accounting for the nesting structure is critical because observations within higher level units are more similar than observations across those units; since lower level units share common characteristics and influences from the higher level units, they are not independent from each other. For instance, in IB, subsidiaries are nested within the multinational firm, which is in turn hierarchically nested within its home country. Lower level units may, however, belong simultaneously to multiple higher levels (i.e., industries and countries). To the

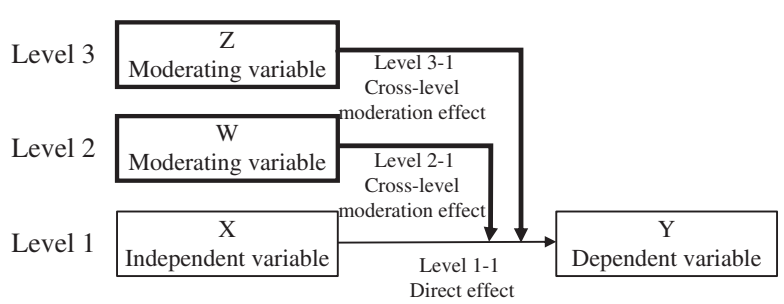

Figure 3 Typical relationships in a cross-level moderation model.

Note: The thicker lines are the relationships of focus.

extent that industries are not country specific but rather global in nature, the resulting structure is non-hierarchical or cross-classified, since each firm uniquely belongs to a combination of both home country and industry levels (for a discussion of different nesting structures in IB research, see Nielsen \& Nielsen, 2010). In IB, upward cross-level influences can be theorized (e.g., multinational firms influencing a host-country institutional environment via lobbying and non-market strategies); however, such influences are typically main rather than moderating effects. Clear specification of the levels of theory and variables helps conceptualize the nature and direction of cross-level relationships.

Figure 3 depicts a typical hierarchical nesting structure with three levels (e.g., subsidiaries within the multinational firm, nested within the home country institutional environment), allowing for simple Level 3-1 and Level 2-1 cross-level interactions.

Figure 3 is, however, an oversimplification of the reality surrounding cross-level interaction, as several additional relationships must be recognized and discussed. First, Levels 2 and 3 moderator variables $(Z, W)$ may also exert direct (downward) influence on the dependent variable $(Y)$. Such potential influences must be acknowledged and accounted for both theoretically and empirically. Moreover, the potential for reverse or symmetrical interaction effects should be ruled out. Multilevel modeling can help identify the directionality of the interaction effects in that it is logical that the contextual variable moderates the relationship between lower level variables (Aguinis et al., 2013). However, the theoretical rationale for directionality of interaction effects must still be specified, with constructs and measurement treated accordingly (Klein, Dansereau, \& Hall, 1994). Multilevel studies of this kind can develop and test hypotheses pertaining to three types of relationships: (a) lower level direct effects (Level 1-1); (b) cross-level direct effects (Levels 2-1 and 3-1); and (3) cross-level interaction effects (Levels 2-1 and 3-1). Manuscripts with cross-level interactions tend to discuss the direct 


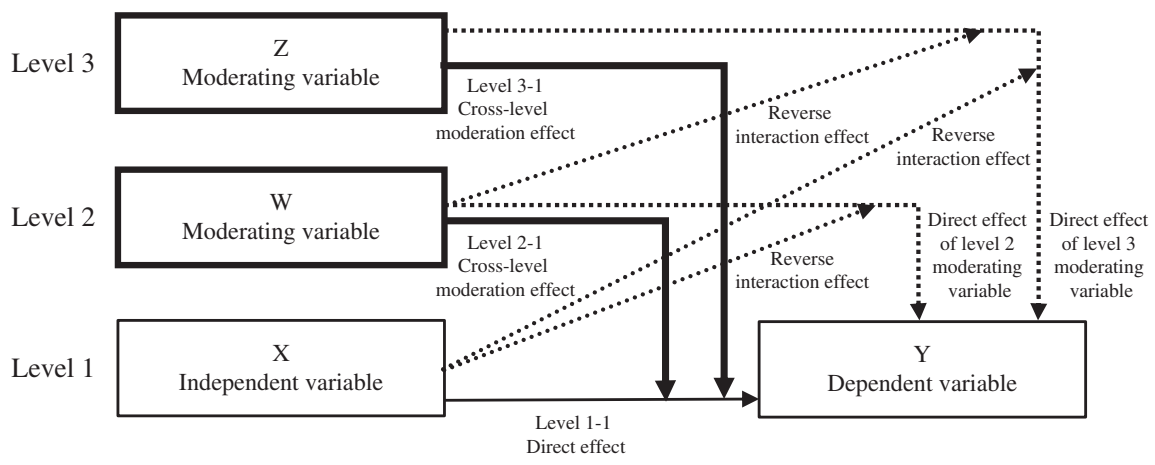

Figure 4 Additional relationship in need of theoretical explanation when analyzing a cross-level moderation model. Note: Dashed lines indicate alternative relationships to consider.

effect first followed by the moderation of this effect by Levels 2 and 3 cross-level interactions. Figure 4 illustrates these additional relationships associated with cross-level interactions.

Similar to the previous discussion, we offer a set of concrete steps on how to develop theoretical insights for authors considering cross-level interactions:

1. First, specify the focal unit of analysis of the study. This is typically determined by the analytical level of the dependent variable (e.g., firm for studies analyzing firm performance; team for studies analyzing innovation in teams) and represents the level to which generalizations are made. This first step is important, as the unit of analysis determines the appropriate level of associated theoretical constructs and helps avoid misattribution of effects, commonly referred to as "fallacies of the wrong level" (Rousseau, 1985: 5).

2. Second, specify the hierarchy and nature of theoretical nesting (e.g., individuals, teams, firm, industry, country, region, etc.). Nesting is important because lower level units share commonalities with higher level units. You need to determine the appropriate levels at which your phenomenon is operating and where you plan to draw the boundaries of the theoretical extension. For example, you may be interested in analyzing subsidiaries, nested within a multinational firm that is in turn headquartered in a particular country. In such a three-level hierarchical model, the multinational firm's headquarter and/or home country characteristics may act as moderators on the relationship between subsidiary characteristics and strategic choice (e.g., Goerzen, Asmussen, \& Nielsen, 2013).

3. Third, choose relevant independent variables from theories at each level of nesting and clearly specify their relationships with the dependent variable (upward or downward). In the selection of variables, take into account how the theory to which they adhere, or its extension, operates at the level of analysis of the focal unit. Explicit integration of theories that span different levels holds great potential for facilitating new theory generation; however, careful attention must be paid to how theoretical constructs operate across levels without losing their substantive meaning. For instance, trust at the institutional level may mean something different than inter-organizational or inter-personal trust (Nielsen, 2010).

4 . Fourth, model the within-group variance by specifying the lower level (Level 1-1) direct effects. Identify the theoretical mechanisms explaining these effects and make arguments consistent with the level of theory (i.e., the dependent variable). Direct effects hypotheses at the lower level are typically specified in the same manner as regular hypotheses, using statements like "predictor $X$ is positively/negatively associated with outcome $Y^{\prime \prime}$, or "the influence of predictor $X$ on outcome $Y$ is positive/negative".

5. Fifth, choose relevant moderator variables from theories at higher (lower) levels. If the moderator variable has a relationship with the dependent variable, clearly distinguish the theoretical arguments for the main effect from those for the moderating effect.

6. Sixth, model the between-group variance in intercepts by specifying cross-level (Levels $2-1$ and 3-1) direct effects. Identify the theoretical mechanisms explaining these effects and make arguments consistent with downward (upward) direct influences. Cross-level direct effects hypotheses are often specified using statements like: "industry competition negatively influences 
firm performance", or "host country governance quality is positively associated with non-equity entry mode".

7. Seventh, model the between-group variance in slopes by specifying cross-level (Levels $2-1$ and 3-1) interactions. Identify the theoretical mechanisms that explain how and why the nature or strength of the lowest level relationships changes as a function of the higher level moderator. Crosslevel interaction effects hypotheses are often specified using statements like "the relationship between firm international diversification and performance varies with home country institutional quality such that firms originating from countries with higher quality institutional environments are more likely to benefit from international diversification than firms originating from countries with lower quality institutional environments".

8. Eighth, rule out reverse interaction of the independent variable on the cross-level direct relationship between the moderator and the dependent variable. The statistical analysis software cannot detect the direction of relationships and theory must guide this choice. Cross-level interactions typically involve contextual variables at higher levels and this often makes it easier to rule out reverse interaction from a logical standpoint; it is far more likely that industry- or country-level factors moderate the relationship between firm strategy and performance than it is that direct effects of industry or country characteristics vary with one firm's strategy or conduct. Depicting the research model in a figure helps clarify theoretical nesting and the nature and direction of relationships and interactions.

9. Ninth, return to theory when interpreting the results. Multilevel research offers the opportunity to extend theory by bridging or integrating theories from different domains. You need to explain how the cross-level effects (direct or interaction) change our understanding of the theoretical mechanisms that link concepts in a model. It is often useful to examine to what extent the crosslevel interactions modify both the theory of the focal unit of analysis and theories at higher levels from which the moderators are drawn.

\section{CONCLUSIONS}

Interaction effects are increasingly being analyzed in research papers. This is especially the case in IB, because the cross-disciplinary nature of the phenomenon enables researchers to generate new insights by analyzing the boundary conditions of well-known relationships that have hitherto been explained in a domestic setting. Given the theoretical challenges posed by interaction effects, in this editorial we provided a sequence of steps that researchers can follow to explain interaction effects within and across levels of analysis. These steps should be viewed as tools that can be adapted and modified depending on the specific research question and nature of data, rather than strict steps that all submitted papers must follow. The objective of these suggestions is to create papers that provide deeper discussions and extensions of theory. This editorial complements other editorials that have discussed how to develop theory in IB (Bello \& Kostova, 2012; Cheng et al., 2009; Cuervo-Cazurra, Caligiuri, Andersson, \& Brannen, 2013; Thomas, Cuervo-Cazurra, \& Brannen, 2011) and how to incorporate advanced statistical techniques (Chang, van Witteloostuijn, \& Eden, 2010; Peterson et al., 2012; Reeb, Sakakibara, \& Mahmood, 2012).

\section{ACKNOWLEDGEMENTS}

We thank Editor John Cantwell and two anonymous reviewers for useful suggestions for improvement. Alvaro Cuervo-Cazurra thanks the Patrick F. and Helen C. Walsh Research Professorship and the Robert Morrison Research Fellowship at Northeastern University for financial support. All errors are ours.

\section{NOTE}

${ }^{1}$ We use the term mechanisms to denote underlying theoretical processes (or reasons) for certain proposed effects. This is different from the use of mechanisms to denote intervening (mediating) variables in a causal chain of relationships (see Baron \& Kenny, 1986).

\section{REFERENCES}

Aguinis, H., \& Gottfredson, R. K. 2010. Best-practice recommendations for estimating interaction effects using moderated multiple regression. Journal of Organizational Behavior, 31(60): 776-786.

Aguinis, H., Boik, R. J., \& Pierce, C. A. 2001. A generalized solution for approximating the power to detect effects of categorical moderator variables using multiple regression. Organizational Research Methods, 4(4): 291-323.
Aguinis, H., Gottfredson, R. K., \& Culpepper, S. A. 2013. Bestpractice recommendations for estimating cross-level interaction effects using multilevel modeling. Journal of Management, 39(6): 1490-1528.

Baron, R. M., \& Kenny, D. A. 1986. The moderator-mediator distinction in social psychological research: Conceptual, strategic and statistical considerations. Journal of Personality and Social Psychology, 51(6): 1173-1182. 
Bello, D. C., \& Kostova, T. 2012. From the Editors: Conducting high impact international business research: The role of theory. Journal of International Business Studies, 43(6): 537-543.

Boyd, B., Haynes, K. T., Hitt, M. A., Bergh, D.A., \& Ketchen, D. J. 2012. Contingency hypotheses in strategic management research: Use, disuse or misuse? Journal of Management, 38(1): 278-313.

Buckley, P. J., \& Casson, M. 1976. The future of the multinationa enterprise. London: Palgrave Macmillan.

Carte, T. A., \& Russell, C. J. 2003. In pursuit of moderation: Nine common errors and their solutions. MIS Quarterly, 27(3): 479-501.

Chang, S. J., van Witteloostuijn, A., \& Eden, L. 2010. From the Editors: Common method variance in international business research. Journal of International Business Studies, 41(2): 178-184.

Cheng, J., Henisz, W., \& Roth, K. 2009. From the editors: Advancing interdisciplinary research in the field of international business: Prospects, issues and challenges. Journal of International Business Studies, 40(7): 1070-1074.

Cohen, J., Cohen, P., West, S. G., \& Aiken, L. S. 2003. Applied multiple regression/correlation analysis for the behavioral sciences, 3rd edn. Mahwah, NJ: Erlbaum.

Cuervo-Cazurra, A., \& Dau, L. A. 2009. Promarket reforms and firm profitability in developing countries. Academy of Management Journal, 52(6): 1348-1368.

Cuervo-Cazurra, A., Caligiuri, P., Andersson, U., \& Brannen, M. Y. 2013. From the Editors: How to write articles that are relevant to practice. Journal of International Business Studies, 44(4): 285-289.

Edwards, J. R. 2010. Reconsidering theoretical progress in organizational and management research. Organizational Research Methods, 13(4): 615-619.

Frazier, P. A., Tix, A. P., \& Barron, K. E. 2004. Testing moderator and mediator effects in counseling psychology research. Journal of Counseling Psychology, 51(1): 115-134.

Goerzen, A., Asmussen, C. G., \& Nielsen, B. B. 2013. Global cities and multinational enterprise location strategy. Journal of International Business Studies, 44(5): 427-450.

laccard, J., \& Turrisi, R. 2003. Interaction effects in multiple regression, 2nd edn. Thousand Oaks, CA: Sage Publications.
Johanson, J., \& Vahlne, J. 1977. The internationalization process of the firm: A model of knowledge development and increasing foreign commitments. Journal of International Business Studies, 8(1): 23-32.

Klein, K. J., Dansereau, F., \& Hall, R. J. 1994. Levels issues in theory development, data collection, and analysis. Academy of Management Review, 19(2): 195-229.

Mathieu, J. E., \& Chen, G. 2011. The etiology of the multilevel paradigm in management research. Journal of Management, 37(2): 610-641.

Nielsen, B. B. 2010. Multilevel issues in strategic alliance research. In T. K. Das (Ed), Researching strategic alliances: Emerging perspectives 57-76. New York: Age Publishing.

Nielsen, B. B., \& Nielsen, S. 2010. Understanding the internationalization-performance relationship: A multilevel approach. In T. Devinney, T. Pedersen, \& L. Tihanyi (Eds), Advances in international management. New York: Emerald.

Penrose, E. T. 1959. The theory of the growth of the firm. Oxford: Oxford University Press.

Peterson, M. F., Arregle, J. L., \& Martin, X. 2012. Multilevel models in international business research. Journal of International Business Studies, 43(5): 451-457.

Reeb, D., Sakakibara, M., \& Mahmood, I. P. 2012. From the Editors: Endogeneity in international business research. Journal of International Business Studies, 43(3): 211-218.

Rousseau, D. M. 1985. Issues of level on organizational research: Multi-level and cross-level perspectives. Research in Organizational Behavior, 7(1): 1-37.

Shieh, G. 2009. Detecting interaction effects in moderated multiple regression with continuous variables: Power and sample size considerations. Organizational Research Methods, 12(3): 510-528.

Snijders, T., \& Bosker, R. 2012. Multilevel analysis: An introduction to basic and advanced multilevel modeling, 2nd edn. Thousand Oaks, CA: Sage.

Thomas, D. C., Cuervo-Cazurra, A., \& Brannen, M. Y. 2011. From the Editors: Explaining theoretical relationships in international business research: It's about the arrows, NOT the boxes. Journal of International Business Studies, 42(9): 1073-1078. 